\title{
FROM WE-MEDIA TO I-MEDIA: IDENTITY TRANSFORMATIONS IN THE VIRTUAL WORLD
}

\author{
Alexandr G. Asmolov \\ Lomonosov Moscow State University \\ Moscow \\ Gregory A. Asmolov \\ George Washington University \\ Washington DC (USA)
}

The blogs as the platform for a virtual personality construction are considered in the article on the assumption of the positions of Lev S. Vygotsky's cultural-historical approach. Internet journalism practices are considered as the example for the processes of virtual "I" formation. The authors affirm that the appearance of consecutive and stable "I-representation" in Internet is the necessary condition for a change in dynamics of social nets development from motives which are out of Internet in physical space towards situation when a virtual personality is enough full-fledged to be a motive for new social interactions creation not leaving Internet. As a result a virtual personality turns into a net-creating factor and Internet loses its unoriginality in relation to physical space. Using Lev Vygotsky's "internal speech" concept, the article suggests to consider this interaction as a dairy discourse - "A dialog of internal voices", which turns a virtual personality from the product of self representation into the product of social interaction. The authors affirm that the ability to construct a virtual personality is the integral part for personality formation in the new information society and propose to regard journalism practices as one of the methods of effective self representation in Internet.

Key words: virtual personality, cultural-historical psychology, blogs, Internet journalism, social nets, social media.

\section{A little bit of confession}

This is an article by two authors, one of which is a psychologist, and the other is a journalist. Despite all the difference between these professions we are united by several aspects that determine the logic and the genre of this research paper. 
The first of these aspects is the reference to the methodology of constructivism and cultural historical psychology, which is becoming more often a discourse for inter-disciplinary studies of the personality in the world of communications, including the Internet. This methodology is well reflected in research on hermeneutics, sociology, theory of mass communications as the classic works of Alfred Schütz "The Structure of the Life-World" (2003), Peter Berger, Thomas Luckman "The Social Construction of Reality" (1995), Paul Ricoeur "Oneself as Another" (2008). It is used more and more often both in studies of methodology of personality and in the cognitive psychology of conscience, in the framework of the school of cultural historical psychology, including a work by one of the authors of this article "Cultural Historical Psychology and Worlds' Construction" (1996), in the unifying work by V.F. Petrenko "The Psycho-Semantics as a Direction of Constructivism in the Cognitive Psychology" (2007), in the original study by T.P. Emelyanova "Construction of Social Representations in the Conditions of Russian Society Transformation" (2006). For the authors of the article this methodology of social construction of reality is the fulcrum in understanding the transformations of the identity in the world of Internet.

The second aspect that unifies the authors of the article is the interest in the works that attempt to launch bridges between the journalism, the psychology, and the theory of mass communications, that pertain somehow or other to the understanding of the consequences of the emergence of the World Wide Web, of the cyberspace, of the virtual reality. In addition to the classical works of Marshall McLuhan we will mention in this context the collected articles "Humanitarian researches in Internet" (edited by A.E. Voiskounsky, 2000), the study of N.A. Nosov "Virtual Psychology" (2000), of M.M. Nazarov "The Mass Communications and the Society" (2004), "Media-Psychology Issues" (edited by E.E. Pronina, 2002). These works testify that the journalism, the psychology, the mass communications theory, the methodology of cyberspace studies become intersecting domains of research.

And, finally, the third aspect that unites psychology and journalism in this article is that the authors of the article are father, who was, for his entire life, a psychologist in love with the profession of journalist, and son, who was from his childhood involved in the culture of modern psychology and is spending a part of his life in the Internet world.
Therefore, the analysis of identity transformations in the Internet world that is contained in this work is, in a way, the journalist's own identity transformations self-analysis edited by the psychologist. It is such selfanalysis of identity transformations in a virtual world, subjected to psychological interpretation, has led to the identification of such transformation vector from We-Media to I-Media, to the description of which we proceed hereafter.

\section{The blogosphere}

and its place in the media space

In early 2008 the book "The Cult of the Amateur: How Today's Internet Is Killing Our Culture" by Andrew Keen, a high-tech specialist and a Silicon Valley insider, was published in the USA. In his book, the very name of which is rather expressive, Keen compares the content generated by ordinary Internet users with home pornography, and accused the "amateur bloggers" of corruption of the social values. The picture is rather threatening; however, one of the book's conclusions was that the blogs are not a threat for the traditional media.

The role of the blogs and of the so-called User Generated Media in journalism was thoroughly discussed. They were frequently praised and criticized, so it would just be du mauvais ton to start this discussion over again. On the one hand, the adepts of bloggerism give examples of bloggers that have surpassed traditional journalists, either due to some sensation born from the joint efforts of the blogosphere's collective mind, or due to the speed of information transmission (like it happened, for instance, after the tragedy of the Boeing 737 in Perm, when the blogs content was for a long time the main source of information for the traditional media). As a response, the representatives of the traditional mass media affirm that it is about singular cases and that the blog journalists still have a long way to go to the resources of, and access to, information available to the traditional mass media (not to mention the professionalism and the experience). Of course, in the heat of the moment it is enticing to join this argument and to affirm that it is the methods of content consumption rather than the content quality that are important in this case. After all, actually, one of the main advantages of the traditional mass media as compared to the amateur media is not their ability to get information but the 
ability to process it - to set out the main point, to draw the picture of a day, to place emphases, and to create a concentrate out of the endless ocean of information. And it is this case when the weak points of the user generated platform are most obvious; after all, the consumption of information from blogs and similar informational niches requires the transfer of responsibility for the construction of the picture of the world on the basis of the information flow from an editor to the readers themselves. And a reader, as a rule, does not want this! He has no energy or time to do that. Facing the attempt to form a general picture of the world based on the principle of importance but without clear criteria rather than the specific task to search information on a certain topic, the reader as an Internet user acts by the formula of national Russian fairy tales: "Go to an unknown place and bring an unknown something". Actually, due to the creators of Google and to the user preference sites, this question presumes quite a definite answer: "Go to a place where the majority goes and bring something that everyone brought". We would like to remind that such answer is a sign of known psychological purpose of conformism, depersonalization, and unification. The individual conscience draws back under the pressure of the collective mind. The formulas of search and hierarchy in the access to information try to populate their algorithms with the spirit of the collective mind that must replace the editor, but for a whole number of reasons, related to both content and format, this is a rather doubtful venture. But all this is still the same argument in the same plane - blogs versus papers, Youtube versus television...

The American sci-fi author Robert Sheckley affirmed that it is necessary to be able to ask the question correctly in order to get a correct answer. Is the attempt to compare the traditional media to the new ones, frequently dubbed as "social media", a legitimate one, and, most importantly, a productive one? Since Dan Gillmor, in his famous work "We the Media", proclaimed the revolution under the same motto, the independent journalism was often treated in the first place as a manifestation of a new phase of democracy and freedom of our age. The Gillmor formula became the anthem of new informational technologies as a mechanism of liberalization and a triumph over "gatekeeping" - over the mass media as a doorman in front of the entrance to the public sphere under the aegis of, and close supervision by, the influential persons of our world.

\section{Reasons why the journalists \\ turn to the blogosphere}

But let us forget for a while the discussion about the clash of the two "tectonic" platforms - the traditional media and the user-generated media - and look at the blog journalism from another angle - the angle of personal motives and social-psychological premises. In other words, let's try to use a tool called motivational analysis in psychology, and try to reconstruct, through this analysis, the behavioral scenarios that led to the increase of the importance of the blogosphere in the mass media world. For that we will need, in the first place, to go several years back in time.

No matter how paradoxical it looks in the light of the aforementioned argument, one of the first people who determined the blogosphere as a media space, especially in Russia, were the "traditional journalists" themselves. The employees of various media, many of which were in charge of the news, started using the blogs actively. The blogosphere of the Livejournal (LJ), well known to the Russian readers, was one of the first and most vivid examples of that phenomenon, and not just examples but, in fact, one of the first virtual havens for media turncoats (who, naturally, did not quit their regular professional activity, as a matter of fact). The LJ became not just a space for journalists but a platform for the emergence of some sort of a journalists' community on the basis of the blogs of the media front soldiers. One of the reasons for the emergence of such activity parallel to the traditional informational space was, in our opinion, the absence of control and of any selection of the materials published. The journalists' texts in that space were much more unbound as compared to the genre format requirements, often much longer than allowed by the traditional media space format, and the ideas were often totally free of the dryness and neutrality specific to the news format. Regularly, in different places, the blog posts were captioned with the "uncensored" header, meaning not just the censoring in the classical sense of prohibition to the "non-permitted", but the editorial censoring requiring to cut down the text, to place other emphases, to change the style and the captions, and in general to squeeze the text created in pain and treated as something dear and near in the rigid frames of the employer's media platform.

Till presently all this fits in the blogosphere concept as, in the first place, a space of permissiveness and uncontrolled access to the public domain. From the viewpoint of psychoanalysis the blogosphere could be 
described as a sphere of communicational behavior without control by the superego.

Still, the motives of journalistic breakthrough in the blog space can hardly be reduced just to the overcoming of the content censoring and to the freeing from the superego. Yes, certainly, the blogs hosted more content, to a certain extent, and it was freer and more independent as compared to articles that might appear in the traditional mass media. But another tangible trend appeared on the backdrop of this journalistic freedom of thinking. If in the framework of the news material genre it usually means the reader's meeting with the covered event, in the news blog posts it is, of course, the event, but its structure contains a clear image of the journalist him- or herself, his own ego. These are news under the flag of the first-person pronoun. In addition to the genre changes, the personalization of the news coverage angle was also conditioned by the fact that such news appeared in the framework of a platform, the common denominator of which was the authorship itself, and not the fact that all the covered events occurred within a certain segment of time (daily newspaper or news block). The effect was also amplified by the fact that the traditional news intermingled with news of a totally different nature - descriptions of some events or other in the life of the author him- or herself. Let us give just one of the thousands of examples, maybe a bit radical, when a young and rather well-known journalist published in her blog a comprehensive report on her child birth experience. The post was an incredible success.

Is this related to the fact that the journalists were freed from the editing chains? The freedom from the bondage of editing censure is hardly the only reason of development of a sort of "blog journalism". We would like to mention another reason, although it certainly requires a social-psychological confirmation, as it is definitely not shared by all the journalists and psychologists. The journalism is per se a profession oriented to the work in the public domain. The choosing of this path often hides the ambition to go public, to bring one's own thoughts to a large audience, the motive to personalize oneself in other people (Petrovsky, 1996). However, the journalistic format itself, especially the news, the newspaper format, in most cases makes the journalist's personality play a secondary part. In the best case the author's name is mentioned in the beginning of the article, and in most cases is placed in the end of the article. It is nothing more than a formality. In other words, the news genre often contributes to the depersonalization of the journalist, taking him or her beyond the informational space coordinates system. As we have already mentioned, the mass media revolve around a temporal axis - the morning paper with the results of the previous day, the evening news block on TV, the hourly news on the radio. As a matter of fact, the journalists often remain in the shadows of their texts. And rather few professionals succeed to get to the light out of those shadows. That is why, in fact, the ability to manifest oneself in the framework of a rigid genre sometimes becomes a journalistic art, meaning, in essence, the ability of realization of its own ego in spite of the genre, to leave an imprint of one's ego despite the dullness of the format. The journalist must squeeze in the Procrustean bed of the genre, but to leave a victorious left foot pinkie beyond. However, it is not enough, if taking account of the fact that sometimes the process of information gathering is no less informative and eloquent than the gathered information itself. All this activity of the journalist's personality remains behind the scenes of the public space.

The blogs gave the journalists a new platform. In the framework of the blogosphere the information can revolve not around the temporal axis (from deadline to deadline of some informational product or other), but around the axis of the journalist's personality. Or, if we continue with the psychoanalytic analogies, the Ego triumphs over the Superego in the blogs. The blog is a space where the primary characteristic and the common denominator is the individuality of its owner, i.e. not Gillmor's We-Media, but the I-Media. Thus, on the basis of the blogs platform, a new format of news journalism - the diary journalism - emerged. These were not diaries with descriptions of the current events, but the journalist X's way to cover these events. The reader that accessed these diaries was searching not for the results of the day as in the traditional informational products, but the image of the world through the prism of the opinion of a certain journalist's personality.

A diary is a personal space in the first place. We see in the diary the thing dubbed by Lev Vygotsky as the phenomenon of "internal speech". It is just the way it is - the journalists' lives revolve around news, that is why, when they speak of their lives, these stories also include the way the news reflect the personality's features related to the opinion of the journalists themselves on such events. This can be a narration of the information, or photos from the site of the event, and impression, and a backstage story about the gathering of the information. The main thing 
in this case is that the narrative of the world picture description is egocentric. In our opinion, the change of the news text coordinates system from temporal to diary-personal - rather than the freedom from the bondage of censoring became one of the most interesting contributions of the blogs to the development of the mass media.

The diary journalism has also given life to new models of information consumption. A newspaper or any other format of news media used to represent, in the first place, a decision on the events to tell about and on the events not to tell about, i.e. was a function of the work of the editor as of the person in charge for the composition of the informational product. Now, the reader can for him- or herself make a net out of the journalists' blogs in order to catch information based on the choices and opinions of journalists (although frequently - in the framework of their editorial tasks) rather than on the interaction between a number of events within a specified period of time and the editor's decision.

However, this model may not pretend to play the role of an alternative to the traditional media because of the relative fortuitousness of the informational topics lighted by the I-media limelight, on the one hand, and because of the reader's inability to take responsibility both as information consumer and as editor. Receiving news information from blogs, the reader, on the one hand, obtains the personalized opinion of the blog post author on the event, i.e. the personal opinion of the blog's author, but, on the other hand, given that a blog is just one view on one event, it cannot represent an integral picture of the world i.e. a sum of important events that occurred, for example, in the last 24 hours - something that the traditional mass media can provide. Today different models of use of blogs as an information source emerge, but they shift more and more from the idea of alternative mass media to a complex system of interactions, the core of which is, anyway, the symbiosis with the traditional mass media. The latter depict the general features of an informational picture, whereas the former comment and expand the perspectives of view and the space of the narrative, placing ego-emphases in the informational flow.

Still, is the analysis of the journalists' role in the blogs a legitimate one for the analysis of the blogosphere's role in the society? Describing the blogosphere as a chaos of mediocrity and inaccuracy, and speaking of the destructive role of the blogs, Andrew Keen does not have the journalists in mind. Indeed, the journalists are a frequent occurrence in this informational space, and if they became one of the pioneers of the blo- gosphere in Russia, due to a whole number of social and cultural conditions, the things were different in the global blog world. In the USA the blogs were originally deemed to be a place populated by teenagers, and only in the relatively recent times the other social groups, including the journalists, started penetrating this space. In our opinion, it is not correct to oppose the blogger journalists as people having professional text-writing skills and writing texts interesting to a large audience, to the ordinary bloggers that Andrew Keen writes about. It is rather the other way round - in this case the analysis of the motives of the journalists that started writing in blogs must help to understand a more wide and global phenomenon.

\section{From mask to personal identity \\ in the Internet. Identity and social networks}

The user-generated journalism was gaining momentum by far not only by the efforts of offline journalists. Very soon people who notified on some news or other emerged in the blogosphere, not being employees of traditional media organizations. Who were those people? Failed journalists? Idealists who wanted to change the society and tell the truth to the world? Apologists of Dan Gillmor's ideas like "Media Are Us"? In our opinion, the key to the understanding of their personalities is the motivational analysis of the journalists' behaviour that we have analyzed above (Asmolov, 1996). However, in order to understand this affirmation, we need, in the first place, to consider the process of personality presentation evolution in the framework of the Internet.

Those of us who were Internet users before the dawn of this century remember such a communication tool as the Inter Relay Chat (IRC). When using such chat programs or dwelling in chat rooms, most of the participants of Internet communication did not use their real names back then. We were changing masks; we were playing not just with our names, but also with age, sex, discovering new boundaries of our virtual ego. As soon as in the mid-nineties the first major research works on the transformation of the human personality in the virtual world were published. Thus, for instance, Sherry Turkle spoke about the "multiplicity" and "instability" of the representation of the human ego in the virtual communication environment in her famous book "Life on the Screen" (Turkle, 1995). In 2000 Mark Poster published his article "CyberDemoc- 
racy: Internet and the Public Sphere"1, where the researcher introduced the notion of "mobile identity" (Poster, 1995). He affirmed that the departure from the physical space completely changes the rules of political game, as the notion of sovereignty belongs in exclusivity to the world of the stable and the corporeal.

Another system of relationships, of the emergence of which M. Poster spoke about, was indeed starting to form in the virtual space, acquiring features of a new hierarchies system. The netocracy - such name was given to this reality (or, rather, yet to the idea about it) by A. Bard and J. Söderqvist in their book with the same name (Bard, and Söderqvist, 2002). By developing the popular idea of informational revolution, the authors described a reality where information is capital and the owners of such information, those who take over the crossroads of informational flows, become "informational tycoons".

However, the networks world does not tolerate mobile identities. The accuracy and value of information depends, to many extents, on the ability to identify the source. In other words, the importance of a network node is in many ways determined by the stability of the virtual personality and by its status and reputation. In other words, the networks world contravenes the logic of Bakhtin's carnival (Bakhtin, 1979), as the carnival is a form of disdain to the value of the information. As we know, the information is always problematic when its source is masked, and when the source starts changing masks, the value of the information is swiftly reduced to zero.

Thus, we can presume that starting with the early $21^{\text {st }}$ century, the development of the Netocracy, i.e. of the society where the status is determined by the position in the net, has led to the Internet becoming a platform for the restoration of the identity stability. Taking account of the chaos of identities and of the culture of mobility preceding this period, it was not so easy to find and determine one's stable Ego. A stable identity in the virtual world was emerging gradually, as if feeling about itself in the unsteady space devoid of any concreteness, from the chats where the identity was changing with every access, to the messenger programs (like, for instance, ICQ), where, at first, it was a custom to use made-up names "nicknames", however, the nickname remained stable from access to access to the virtual space. The emergence of blogs also started with a very tangible presence of pages, the holders of which were anonymous, despite

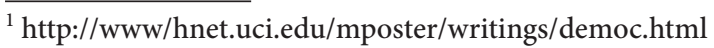

the constant bond between the blog content to a specific nickname. Simultaneously, a practice of double life, the so-called blog virtuals - emerged, where a person had two blogs, one where his or her identity was known, and the other where he or she was masked. However, in time the flirt with one's own anonymity was becoming less and less fashionable and interesting. The readers were looking for real heroes, albeit in a virtual space. The formation of the identity was visible in the e-mail addresses as well. If in the first years of the Internet the real names in the e-mail addresses were a very rare phenomenon, today the formula "name-dot-surname" became one of the most popular and widely spread.

However, a decisive moment in the formation of identity in the Internet became the emergence of platforms for social networks, be it LinkedIn, Facebook, or the Russian Odnoklassniki.ru or Vkontakte.ru. The idea of social network is initially built on the need to present one's own real identity, or, more precisely, of the personal identity, in the network. If you present yourself under a made-up name, you will have very few chances to expand the network i.e. to help your friends find you or confirm your request to include them in your network. Thus, the networks world became a total antipode to the Bakhtin's carnival that the Internet represented as recently as ten years ago.

However, the social networks like LinkedIn or Odnoklassniki had one important feature that is worthy of special attention. These networks contained just the external shell of the identity, hereas the content of such identity was situated in the offline world. In other words, people were forging new ties in the social networks of the Interned based on some offline information or other. It could be a person who they studied with, worked with, met with in a café or at a party, but the invariable thing was that the identity content carrier was the "world outside the Internet", whereas the Internet contained just the shells - the names, surnames, photos, telephone numbers, and addresses.

For all that, the use of the Internet space as a universe of growing social networks requires us to venture beyond the limits of logic oriented only to the identity with its content situated in the offline. This, while the social networks are a space of ties between the "nodes of personalities", the Internet also needs a space for the "content of identities", some sort of a "vessel for the personality". In other words, it must be a space where the personality can fully open up its content - its inner world, so that it could be a reason to create social ties without knowing the person in the real world. 


\section{The diary as a space}

of personal-notional communication

In the context of the cultural-activity psychology created by L.S. Vygotsky, A.N. Leontiev, and A.R. Luria, the diary is, perhaps, one of the best candidates for the role of a "vessel of the personality" beyond the limits of the human conscience. In the diary genre the personal senses, the "meanings-for-me" prevail over the faceless meanings, the "meanings-for-all" (Leontiev, 1975). The diary is a special sort of "auto-communication", when I speak to myself. The diary as a dialog with oneself is built on the basis of the laws similar to the laws of internal speech (Vygotsky, 1982). In other words, the diary is not just a platform for the personality to express itself, but to develop dynamically. The diary as a form of presentation of the internal speech reflects, to the biggest extent, the motivational "secret plan of the conscience" (Vygotsky, 1982), the "polyphony of the conscience" that was so vividly described by M.M. Bakhtin. Thus, the virtual diary as a form of creation of an online identity allows opening oneself up, by using the entire range of "intimacy" of information about oneself: from the public and the all-known to the most secret and inmost. The process becomes especially dynamic as the interactivity allows including other bloggers in the "inner speech", which creates a unique phenomenon - a dialogue of the "inner voices", a discussion in a diary.

The blogs became the very vessel - the platform - for the content of the personality in the virtual world. With the development of the social networks and the change of the condition of identity from gaseous (the chats) to something liquid (permanent nicknames) to solid (real names), the blogs acquired a new function. It was not just a distraction. The Internet diaries as a virtual platform for the development of the virtual representation of the personalities acquired an important function - they became the online bulwark of the personality i.e. an alternative (in relation to the physical world) reason for the development of the social networks.

However, in order for the blog as a virtual platform of the personality to be a reason for the development of a social network, a condition must be met - the blog must be interesting. In other words, the blog as a platform of the personality must motivate the desire to include the owner of that blog in the social network without being acquainted to him or her in the non-virtual world. And here a question emerges how to make the blog content attractive? The personality has many sides of manifestation in the real life. Let's suppose that two people get acquainted in a club. The interaction is conditioned by the location in a common space where there is a limited number of people, and not necessarily by motives of verbal content nature. The virtual space hosts millions at a time, and therefore there are no restrictions for contact, i.e. the competition is higher than in real space. Besides, if in real life our personality is in many aspects conditioned by our behavior that may sometimes be natural and spontaneous, and not a function of some plan thought up in advance, in the virtual space the things are somewhat different. In fact, the blogger needs not just to "retranslate" his ego in the "virtual vessel" of the diary, but to construct this personality, i.e. to be the editor of him- or herself, with all the resulting functions known in the journalism.

However, there is an advantage related to the genre. The blog as a diary space can open up the person to a deeper extent than the possibilities offered by a meeting in the real space of life. When you meet someone in a noisy club, trying to yell louder than the music, after several attempts you can find out each other's names. And in the case of a blog you can read the chronicle of a human life with the example of a specific person. Still, let us emphasize once again that for that purpose the blog must be, first of all, valuable and interesting. And the attractiveness of the content is the very problem faced by the blogs.

The problem of "content crisis" of the blogs was once described in the notorious column by the journalist Valeriy Panyushkin in the Vedomosti newspaper, that was headed by a phrase that made the tour of the entire Russian-speaking blogosphere: "People, I read your diaries: you're creeps and losers". 2 Supposedly, to some extent the column by V. Panyushkin is a provocation. But it is a rather accurate description of the personality crisis in its virtual reflection: "The average user of the Livejournal may fail to publish an outburst of despair for years in his or her diary; it just contains some half-hearted whining. No outburst of anger for years, just grumbling. For years - no post brimming with happiness or joy, just petty successes: found a new job, bought a new dress. For years - no compassion for someone else, except oneself.

\footnotetext{
${ }^{2}$ http://friday.vedomosti.ru/article.shtml?2008/05/15/12334
} 
No compassion for anybody else to the extent of crying, and, to give it some thought, not much compassion for oneself either. No news for years: the bloggers willingly post links to all sorts of articles in the press in their diaries, but they don't see any events or people around themselves" (Amzin, 2008). In other words, according to V. Panyushkin, the blogosphere is affected by the disease of the common conscience. But in the context of the social networks development this is not just the emptiness of virtual personalities. This is the absence of virtual premises inside for the development of social networks. You can make a fair objection: "Like personalities, like reflections". But in the offline space this emptiness is compensated, covered by the superficiality and by the social roles. And in the virtual diaries world it is shown as it is through the translation of personal meanings.

The more the Internet is developing, the more it takes over various spheres of our lives, the more time we spend in the virtual space. Therefore, the construction of one's virtual personality is not just a whim of leisure. It acts as a necessary condition for the social development of the personality. That is why the question about how to make the blog attractive as a platform for the virtual ego becomes a question of fundamental importance.

Let us discuss in more detail the potential resources of the "personal content". On the one hand, the virtual diary can become a reflection of the depth a person's inner world, of his thoughts, doubts, and emotions, of his personal meanings. These may be as inner intimate feelings, as well as analyses of the events happening around the person, acquiring most diverse genre forms from literary forms to forms specific exclusively for diaries. The transformation of one's inner world in blog content, so as not to make it "half-hearted whining", or something too intimate, or the stirring of interest by analyzing something without basing on the already existing reputation of an expert in some domain (i.e. without preliminary advertising of one's analytic abilities), but trying to create such reputation in this way - these are extremely complicated tasks.

There are other methods to increase the attractiveness of the blogs, for instance, the posting of someone else's content. Indeed, the copypaste practice is a very frequent occurrence in the blogosphere, and this is not necessarily a negative phenomenon. The desire to share something that you liked and the function of monitoring of a decent content for your friends is a totally legitimate practice. But the repetition in most cases cannot be a premise for the development of a network as it does not cope with the competition with its likes. Another option is some form of pornography (textual or visual) or other. One can hardly argue, as there is exclusivity and intimacy of content able to attract a large audience. However, such kind of content creates networks of a very specific nature around it, and drives away an entire range of other possible connections, which fact is no less important.

Still, there is another resource for the content, which, according to the famous psychologist K. Lewin, would acquire a "stimulatory nature" - would carry a positive attracting valence (Bard, 2002). Such a resource is a daily life rich in events. In other words, the creation of one's virtual personality and the stirring of interest to it are possible by narrating the events happening around this personality in the real world. In such cases people who, for instance, work in places with high eventfulness (policemen, emergency doctors, firemen), and are able to narrate them without fearing to lose their jobs (as it happened to a flight attendant who was keeping a blog and telling stories about her work), are in a ay lucky. An illustrative example is the live journal of a militia man who worked in the Moscow subway. Such blogs can also be kept by deputies of the parliament, although in such case this is not just a personal space but also a tool of political promotion. For all that, this is not a violation of the customary rules of the game. After all, the politicians are people who construct their personality on a daily basis in the public space. However, in general, given the number of reasons mentioned above, the narration of the stream of events in the "professional life" as "personal content" is rather limited for many professions.

\section{Eventfulness of life - a leading motive \\ of a journalist's professional activity}

There is just one profession - the journalism - where the search and the account of events pretending to have an interesting content are one of the main motives of professional activity. In their work they have to deal with substance that allows both covering the events flow and using it to represent its own personality, with maximum dynamicity and to full extent. That is why it is not a coincidence that the journalists have become, in many respects, pioneers of the blogosphere development as 
a space for the construction of one's own virtual personality, of the own virtual ego. But what should the common people do as they suffer of lack of both internal and external "raw material" to build their virtual personality? The answer is simple - to search for events in the outer world and to describe them, "beyond the barriers", as Boris Pasternak used to say, and beyond the regulations of the social life. It means that they should, in fact, search for interesting events that may be described or photographed, with photos posted in the blog, and thus to make another contribution to the construction of one's own virtual personality through the experience of the world around and its reflection in the own individuality. It means in essence that today the development of the self as a virtual personality requires from everyone to be some sort of a journalist.

It seems like a paradox: to speak of the Other in order to build the self. But this is a paradox only in the coordinates system of the "common sense". In phenomenological philosophy, in hermeneutics, in cultural psychology the personality generation vector is set - from the Other to the ego, from inter-subjectivity to intra-subjectivity, from social identity to personal identity. And the construction of identity in the social networks is based on the same psychological logic - the "growth of sociality" from Us to Ego (Asmolov, 2007; Mikhailov, 1997; Ricoeur, 2008; Vygotsky, 1982). The information in the outer world is some sort of "ego-resource". After all, if the "substance" of the personality in the social space is to some extent an enigma of the ego, then the personality in the virtual space is a data bank, the personality is information, the sum of letters, images and sounds represented by a digital code. That is why we actively form ourselves in the online world through our perception of the outer world. The information about the outer world can have an imprint of the ego, because any retranslation of the informational picture contains choice and interpretation. The latter, i.e. the presentation of information about an event through the prism of a certain interpretation, is known to the specialists studying the media as "framing" (selection of frames). But the very fact of selection of some event or other for description already bears a significant informative load. We would call it "agenda setting" in the language of mass communications theory, which means the determination of the agenda in the context of construction of one's own personality. In other words, the description of some flow of physical events in the virtual space is a structure of the world that surrounds us, and contains both this world and ourselves. The main conclusion we can make is that the construction of a virtual ego requires an active search for information in order to retranslate in the in the public online sphere. Such social practice has a name - journalism.

In autumn 2008 Technorati, the leading Internet-site in the domain of blogs search and monitoring, published a new statistical research on the global blogosphere (Voiskounsky, 2000). Among a large quantity of various data there is a fact that is amazing, in our opinion. According to the Technorati report, a half of the bloggers attend various events purposefully in order to cover them in their blogs. In essence, this is the thing that is in a way the proof of the fact that the blogosphere became a "mass media space". And it is not about the result of such activity i.e. not about the extent to which the content complies with the professional journalistic requirements, but first of all about the social and personal mindsets of the bloggers. The journalism is, among others, the human behavior motivated with the desire to obtain information in order to transfer it to the public domain and to make it available to everyone. In this context the quality of information generated must be of a lesser concern to us. The main thing is that the social and personal mindsets in the blogosphere have obviously changed. The existence of the virtual platform makes the bloggers change their behavior in the real world. The professional journalists, which we started our discussion with, simply need not do this. In the context of the concept of the blog as a mechanism of expansion of social networks the employees of the mass media could combine the pleasant with the useful, more precisely, the useful with the useful. However, all others who were interested in the construction of their virtual ego had to master new forms of behavior.

Thus, the external information is a resource for the development of the personality in the virtual space based on the blogs platform, and the mastering of the journalistic mindsets is a condition for the expansion of one's own social network. In order to fulfill this task successfully, the virtual personality must stay dynamic, i.e. it needs permanent informational replenishment. In other words, the common blogger interested in the development of his or her social network not just by the offline relations, must have some sort of a journalist's lifestyle. Incidentally, this is facilitated by the existing PR practices in a certain way. Some companies 
or other often search for bloggers with social networks in place so that such bloggers would supply them with information that the companies would further distribute, i.e. the bloggers are seen as some sort of mediators between the information source and the public.

The emergence of such new mindsets is not limited by the emergence of another type of social behavior among the bloggers. The journalism is not just a targeted gathering of information, but also a special model, or even an ideology of perception of the outer world. Ideally, the responsibility for the bringing of some picture of physical reality to the potential consumer of information means that the journalist is the one who must see the event with his or her own eyes, the one who does not rely on mediation in the transmission of information that is important to him or her, the one who creates the own opinion based on the presence at the site of the event. In other words, the journalist is a refusal from the passive position in the obtaining of information. And in this case the role of the informational technologies, as a stimulus for the virtual personality, is dual. On the one hand, they create motivation for an independent information search and allow making this information public. On the other hand, they offer a large range of informational manipulation mechanisms (for instance, by means of visual editors and three-dimensional graphics). It was Norbert Wiener who demonstrated that a true informational picture was the basis for the survival of any system. That is why the ability to not allow the new technologies to become an instrument of conscience manipulation, the motivation and the ability to get information by using one's own eyes, become an existential issue in the informational society.

The process triggered by the social networks is much more complex than the simple creation of motivation to search for information especially for blogs among the common Internet users. The logic of formation of journalistic mindsets is comprehensively shown by the famous formula of the Canadian media researcher Marshall McLuhan: "we create technologies that create us" (McLuhan, 2003). According to the opinion of the Portuguese researcher, presently - professor of the Toronto University, Ana Viseu, M. McLuhan, without knowing it himself, actually became a direct follower of the school of cultural psychology founded by L.S. Vygotsky (Viseu, 1999). We must note that A. Viseu, when analyzing the transformations of personality in the social networks world, is using the term "electronic identity" based on the works of M. Cole, an American psychologist, a known follower of L.S. Vygotsky and A.R. Luria (Cole, 1997).

A. Viseu, who became in 1999 one of the first researchers that used the cultural-historic approach in the analysis of personality in the virtual world, affirms that a unique situation emerges in the cyberspace. The boundary between the personality and the social environment is erased and it becomes unclear where the person is and where the cultural artifacts (a term by M. Cole) that surround the person are. That is why, in the opinion of Ana Viseu, the virtual world takes the process of interiorization - the growing of the social space into a personal space (L.S. Vygotsky), the manifestation of the culture in the features of the human personality - to another level. It means that the change of our behavior in the social world i.e. the mastering of the journalistic behavior patterns and the evolution of information consumption methods is not just a process of formation of our virtual personality but a transformation of our personality as a whole. It is not just us who break into the virtual world with our identity, but also the virtual world that breaks into us, building up and expanding the space of our egos.

We have examined three basic elements of the system in the framework of which the common bloggers are more and more frequently using the journalistic practices. First, in the relations between the offline and online worlds people play the role of a sort of mechanism to transfer information from the real world into the virtual world by setting it out in the form of digital code and publishing it on a platform available to everyone. Second, the transfer of information from the physical world into the virtual space, somehow or other leaves the "imprint of personal contribution" (Petrovsky, 1996) on the information - the trace of the person who processed it, i.e. the fact of the information processing through the prism of the Ego makes it unique and thereby transforms it into an element of virtual personality construction. And finally, third: the content posted in the diary space (just like, in fact, on any virtual platform that has an identity connected to a certain person) plays a network-forming role. In other words, the content fills the shell marked by the external parameters of the node in the network, thereby attracting new ties to it. This aspect also contributes to the development of a virtual personality as the "personality in the network" is a phenomenon derived from its content and its interactions as the interactions also generate new content. 
We live in the age of formation of the virtual identity. As a matter of fact, it is about parallel processes - the transposition of the outer world in a digital code and the transposition of the human individuality in a digital code, the creation of its informational imprint in the World Wide Web space. These processes contribute to the gradual increase of the time and of the actions that we initially undertake in the framework of the virtual world, i.e. such actions are initially done in digital code, and therefore do not need "transposition". And if today we talk about the development of the personality due to the informational resources of the offline world, we can only guess about the processes of identity construction in a world that is virtual a priori. This enigma becomes even more fantastic if we remind ourselves of the development of the three-dimensional reality technologies. The first trends of such changes can already be observed in worlds like Second Life, although we are yet hardly able to realize their importance.

However, there is one more trend that we can probably speak about with more confidence. In the recent years it was often mentioned that the Internet world wide network can become an infrastructure for the idea of Noosphere in the sense represented by V.I. Vernadsky and Teilhard de Chardin, author of "The Phenomenon of Man" - the sphere of association of the human minds into a single whole and, for all that, of preservation of the uniqueness of each human individuality. We must note that such noosphere requires a unified informational and communicational space. The transposition of the physical reality into the virtual one and the simultaneous transition of the human activity from the offline to the online contribute to the creation of a unified space where any action must become not just an action but also the generation of information about such action in digital code i.e. to the emergence of a reality where the action is inseparable from the information about the action. Then, the virtual diaries will no longer be a tool for describing the life and for creating our virtual reflection. They will transform into a cognitive world of the personality's conscience. We will live by our diaries that will lose their secondary role in relation to the event described. The human inner world will be more and more an integral part of the public space. And not even the most sophisticated science fiction could describe such transformations of the personality.

Still, information is just a habitat in the new Internet universe. The emergence of the noosphere is not possible until virtual personalities will appear in this habitat and will be interesting enough in order to create networks, without needing to address to the physical world.

As early as today, many social networks, like Facebook, are trying to integrate a maximum number of content-platforms, including the link between the representation of the individual in the net and his or her blog. But the true revolution is to be expected after the emergence of the Network of the Networks, which must allow for unifying various networks and content-platforms in a single space. It is known that the Google laboratories are already working on such a "Super-Net" - the "OpenSocial" platform.

The emergence of such a network may lead to an amazing evolutional leap. If until presently the humanity worked on the task of expanding a specific network, with the emergence of the Network of the Networks the dynamics may reverse. Based on the information processing mechanisms, such a Super-Net will connect people by itself and will weave social networks depending on the tasks set. Thus, the network will transform into a standalone operational system of the collective mind, creating forms of interpersonal connection so that the latter could fulfill the tasks set with maximum efficiency. According to the optimistic concept rooted in the ideology of Teilhard de Chardin, the new models of global networking behavior must not affect the uniqueness of each separate node of the network i.e. of the human personality. However, the radical interiorization, the amalgamation of the individuality with the outer world can give rise to other scenarios that are closer to Orwell's anti-utopias than to the humanistic ideas of the author of "The Phenomenon of Man".

Somehow or other, today we still have a long way to go to the realization of the idea of a "live network" as an operational system of the humanity. Today we still debate on whether the blogosphere is a breeder of immorality and brand it with the label of "cult of the amateur", instead of learning how to become a personality in the new informational world, being born in the physical world, and to stand up for our individuality in the communicational space.

These are some of the directions of the analysis and understanding of the personality transformations in the virtual world. And the journalism in the blogosphere becomes some sort of an experimental interdisciplinary laboratory for the research on such transformations. The understanding of the enigmas of the identity's adventure in the social 
networks still requires a lot of efforts by the collective mind, the specialists in communications theory, artificial intelligence, the psychologists, sociologists, philosophers, that are adepts of one of the most promising paradigms of modern thinking - the paradigm of social construction of reality in our beautiful and fierce world.

\section{References}

Amzin, A. (2008). Vvedenie v blogologiju: Resurs Technorati opublikoval vsemirnyj blog-obzor [Introduction in Blogology: the Technorati Resource Published a Worldwide Blog Review]. From http://lenta.ru/articles/2008/09/24/technorati/.

Asmolov, A.G. (1996). Kulturno-istoricheskaja psikhologija i konstruirovanie mirov [The Cultural Psychology and the Worlds Construction]. Moskva; Voronezh.

Asmolov, A.G. (2007). Psikhologija lichnosti: kulturno-istoricheskoe ponimanie razvitija cheloveka [The Psychology of Personality: The Cultural-Historic Understanding of Human Development]. Moskva: Smysl.

Bakhtin, M.M. (1979). Estetika slovesnogo tvorchestva [Aesthetics of Verbal Creation]. Moskva: Iskusstvo.

Bard, A. and Söderqvist, J. (2002). Netrocracy: The New Power Elite And Life After Capitalism. Stockholm: BooksHouse Publishing.

Berger, P., and Luckman, T. (1995). Socialnoe konstruirovanie realnosti [The Social Construction of Reality]. Moskva: Medium.

Cole, M. (1997). Kulturno-istoricheskaja psikhologija: nauka budushhego [Cultural Psychology - A Once and Future Discipline]. Moskva: Tsenter.

Emelyanova, T.P. (2006). Konstruirovanie socialnykh predstavlenij $v$ uslovijakh transformacii rossijskogo obshhestva [The Construction of Social Representations in Conditions of Transformation of the Russian Society]. Moskva: IP RAN.

Gillmor, D. (2006). We the Media: Grassroots Journalism by the People, for the People. Sebastopol, CA: O'Reilly.

Keen, A. (2007). The Cult of the Amateur: How Today's Internet is Killing Our Culture. New York: Doubleday.

Leontiev, A.N. (1975). Dejatelnost. Soznanie. Lichnost [Activity. Conscience. Personality]. Moskva: Politizdat.

Lewin, K., (2000). Razreshenie socialnykh konfliktov [Resolving Social Conflicts]. Sankt-Peterburg: Rech

McLuhan, M. (2003). Ponimanie media: vneshnee rasshirenie cheloveka [Understanding Media: The Extensions of Man]. Moskva-Zhukovskij: Kanon-Press-C; Kuchkovo pole.
Mikhailov, A.A. (ed.) (1997). Ot Ja k Drugomu. Sb.perevodov po problemam intersubektivnosti, kommunikacii, dialoga [From Ego to Other: A Collection of Translations on the Issues of Inter-Subjectivity, Communication, Dialogue]. Minsk.

Nazarov, M.M. (2004). Massovaja kommunikacija i obshhestvo [Mass Communication and Society]. Moskva: Avanti Plyus.

Nosov, N.A. (2000). Virtualnaja psikhologija [Virtual Psychology]. Trudy laboratorii virtualistiki, 6. Moskva: Agraf.

Panyushkin, V. (2008). Disdain and Compassion. Vedomosti, 17, 104. From http:// friday.vedomosti.ru/article.shtml?2008/05/15/12334.

Petrenko, V.F. (2007). Psihosemantika kak napravlenie konstruktivizma v kognitivnoj psihologii [Psycho-Semantics as a Direction of the Constructivism in the Cognitive Psychology]. In V.A. Lektorsky (ed.) Kognitivnyj podhod: filosofija, kognitivnaja nauka, kognitivnye discipliny. Moskva: Kanon.

Petrovsky, V.A. (1996). Lichnost v psikhologii: paradigma subektivnosti [The Personality in Psychology: The Paradigm of Subjectivity]. Rostov-na-Donu: Feniks.

Poster, M. (1996). CyberDemocracy: Internet and the Public Sphere. In D. Porter (ed.). Internet Culture. New York: Routledge. P. 201-217.

Pronina, E.E. (ed.) (2002). Issues of Media-Psychology. Moskva: RIP-Holding.

Ricoeur, P. (2008). Ja - sam kak drugoj [Oneself as Another]. Moskva: Izdatelstvo gumanitarnoj literatury.

Schütz, A. (2003). Smyslovaja struktura povsednevnoj zhizni [Structure of the LifeWorld]. Moskva: institute fonda "Obshhestvennoe mnenie".

Turkle, S. (1995). Life on the Screen: Identity in the Age of the Internet. New York: Simon and Schuster.

Viseu, A. (1999). A Multidisciplinary Approach to the Mutual Shaping Process in Electronic Identities or "We Shape the Tools and Thereafter They Shape Us" McLuhan. From http://www.yorku.ca/aviseu/pdf\%20files/cybid.pdf.

Voiskounsky, A.E. (ed.) (2000). Gumanitarnie issledovanija v Internet [Humanitarian Researches in Internet]. Moskva: Mozhaisk-Terra.

Vygotsky, L.S. (1982). Sobranie sochinenij v 6-ti tomakh [Collection of Works in 6 volumes]. Moskva: Pedagogika. 